\title{
In Defence of Constructive Empiricism: Maxwell's Master Argument and Aberrant Theories
}

\author{
F. A. Muller
}

Published online: 12 July 2008

(C) Springer Science+Business Media B.V. 2008

\begin{abstract}
Over the past years, in books and journals (this journal included), N. Maxwell launched a ferocious attack on B. C. van Fraassen's view of science called Constructive Empiricism (CE). This attack has been totally ignored. Must we conclude from this silence that no defence is possible and that a fortiori Maxwell has buried CE once and for all? Or is the attack too obviously flawed as not to merit exposure? A careful dissection of Maxwell's reasoning will make it clear that neither is the case. This dissection includes an analysis of Maxwell's 'aberrance-argument' (omnipresent in his many writings) for the claim that science implicitly and permanently accepts a substantial, metaphysical thesis about the universe, which then paves the way for his own metaphysical-realist hierarchyview of science. This aberrance-claim, which Maxwell directs against a widely shared and harmful ideology of science called 'Standard Empiricism', generally has been ignored too, for more than a quarter of a century. Our conclusions will be that (i) Maxwell's attacks on CE can be beaten off, and (ii) his 'aberrance-arguments' do not establish what Maxwell believes they establish, but (iii) we can draw a number of valuable lessons from these attacks about the nature of science and of the libertarian nature of $\mathrm{CE}$.
\end{abstract}

Keywords Constructive empiricism - Metaphysics - Science - Aberrant theories · Standard empiricism $\cdot$ Heraclitism $\cdot$ N. Maxwell · B. C. Van Fraassen

\footnotetext{
F. A. Muller $(\bowtie)$

Faculty of Philosophy, Erasmus University Rotterdam, Burg. Oudlaan 50, Rotterdam 3062 PA,

The Netherlands

e-mail: f.a.muller@fwb.eur.nl

F. A. Muller

Department of Physics \& Astronomy,

IGG, Room 3.08, Utrecht University, Budapestlaan 6,

Utrecht 3584 CD, The Netherlands

e-mail: f.a.muller@phys.uu.nl
} 


\section{Exordium: What is Maxwell's Master Argument?}

\subsection{The Master Argument}

Building on work dating from the early 1970s, during the past decades, N. Maxwell has unflaggingly expounded, in a sequence of papers and in books, a metaphysical-realist hierarchy-view of science crankily named 'aim-oriented empiricism', which he claims "is a synthesis of the general views of science of Popper, Kuhn and Lakatos but is also an improvement over the views of all three". ${ }^{2}$ Logically prior to the exposition and defence of his own philosophical view of science, Maxwell claims to have "decisive grounds" for rejecting a view of science called 'Standard Empiricism', of which Van Fraassen's 'constructive empiricism' as well as varieties of realism are purportedly instances; thereby the need is created for a novel view of science and 'aim-oriented empiricism' is proposed to satisfy this need. ${ }^{3}$ The sole purpose of the present paper is to analyse Maxwell's 'decisive' argument against Constructive Empiricism (henceforth: the Master Argument). Part and parcel of the Master Argument is Maxwell's 'aberrance-argument' for the claim that science in fact makes a permanent substantial metaphysical assumption about the nature of the universe.

We begin with a definition of a view of science called

\section{StandardEmpiricism $(S E)$ :}

(SE1) Science ${ }^{4}$ does not accept any permanent, substantial, metaphysical assumptions about the nature of the universe (independent of the evidence and certainly never in violation of the evidence); and (SE2) the decision to accept or reject a scientific theory is based exclusively on the available evidence.

Presumably SE2 entails SE1, although that will depend on what is meant by 'metaphysical'; until further notice we shall keep both SE1 and SE2 for ease of reference and take them to be a jointly exhaustive characterisation of SE. The global logical structure of Maxwell's Master Argument against Standard and CE is as follows. ${ }^{5}$

P1. Maxwell's Thesis. Science permanently accepts a substantial, metaphysical thesis about the nature of the universe.

C1. Science contradicts Standard Empiricism-from P1 and SE1.

$\mathrm{P} 2$. Constructive Empiricism is a version of Standard Empiricism, i.e. it meets both conditions SE1 and SE2 of SE (1).

C2. Science also contradicts $\mathrm{CE}-$ from $\mathrm{C} 1$ and $\mathrm{P} 2$.

C3. Standard Empiricism must be rejected-from $\mathrm{C} 1-$, and then $\mathrm{CE}$ must also be rejected in virtue of $\mathrm{C} 2$.

\footnotetext{
${ }^{1}$ Maxwell (1974, 1993, 1998, 2002a, 2002b).

2 Maxwell (2005, p. 181).

${ }^{3}$ Maxwell (1993, pp. 61, 81, 1998, pp. 36-38, 2002a, pp. 3-5, 2002b, pp. 263-265). We need not and therefore do not go into Maxwell's 'aim-oriented-empiricism'; see Smart (2000) and Muller (2004) for reviews of Maxwell (1998). Rescher (2000) is in spirit and sometimes the letter very similar to Maxwell's view but he does not even mention a single publication of Maxwell. For CE, see Fraassen $(1980,1989)$.

${ }^{4}$ For the sake of brevity, by "science" we mean the Master Argument "the (overwhelming majority of the) scientific community" unless specifically stated otherwise.

${ }^{5}$ Maxwell (1974, p. 131), Maxwell (1993, pp. 65, 68-69, 78), Maxwell (1998, pp. 46-54), Maxwell (2002a, pp. 3-5).
} 


\subsection{Preliminary Comments}

The following comments on the Master Argument provide us with the opportunity to give a preview of what is coming in the current paper.

(i) A warning is in order: Maxwell's wording of SE and other theses and notions can differ subtly from one publication to another. We start with the most simple and straightforward wordings and analyse his arguments with these; as we proceed, other wordings will be considered and the bearing of these other wordings on the Master Argument and our analyses of it will be investigated (specifically in Sects. 3.3 and 3.5). For reasons of exposition it has turned out best to begin with SE as it stands (1).

(ii) We shall assume that throughout the Master Argument 'acceptance' is used in Van Fraassen's pragmatic sense of voluntary acceptance simpliciter. Acceptance is, then, taken to be the dispositional mental state guiding our behaviour and is (assumed to be) devoid of any overtly epistemic connotations, such as when we consider an accepted proposition to be part of scientific knowledge or involuntarily believing it to be true (although for Van Fraassen, acceptance admittedly has epistemic implications; cf. Sect. 3.1). ${ }^{6}$ We must proceed in this fashion in order not to let Maxwell ab ovo commit the fallacy of equivocation with respect to (Van Fraassen's notion of) acceptance. (In Sect. 3.5, we briefly explore four other notions of 'acceptance', some of which are overtly epistemic.) We report that the distinction between acceptance and belief can be defended on very general grounds, which have nothing to do with empiricism; see Cohen (1992).

(iii) Notice that logically speaking only SE1 of SE (1) is needed in the Master Argument, which implies that criticisms of the Master Argument restricted to SE2 (1) are doomed.

(iv) Who adheres to SE? Maxwell (1993, p. 65) located SE2 in Popper's Conjectures and Refutations. Popper (1963, p. 54): "the principle of empiricism which asserts that in science, only observation and experiment may decide upon the acceptance and rejection of scientific statements, including laws and theories". Besides Popper, Maxwell finds among the card-carrying advocates of SE Max Planck and Henri Poincaré. ${ }^{7}$

Most current philosophers of science underline some version of the Duhem-Quine UnderDetermination Thesis (UDT), according to which any set of phenomena do not fix uniquely a theory that describes or explains those phenomena; there is always a variety of theories that can do so. When we combine UDT with the fact that science accepts a variety of scientific theories, which all philosophers of science will accept, then we must conclude that most current philosophers of science accept SE, because conjunct (SE2) clearly contradicts UDT. This downplays the relevance of the Master Argument. Nonetheless SE may very well be widespread among scientists.

(v) Logic alone does not dictate anyone to reject SE when it contradicts science (C1, $\mathrm{C} 2$ ). More than logic is required to vindicate the final step of the Master Argument (C3), which chooses for science and against SE. We shall see, however, that the nature of the contradiction is such that we shall unhesitatingly rule in favour of science to save us from the putative contradiction.

(vi) In general, a conclusion cannot be more convincing than any of its premises. In case of the Master Argument, these are premises P1 (Maxwell's Thesis) and P2; both of them

\footnotetext{
${ }^{6}$ We call a declarative sentence a statement, and classes of logically equivalent statements propositions. We shall confuse 'statement' and 'proposition' on a regular basis and we apologise for that in advance.

7 See Maxwell (1998, pp. 2-3, 38-45) on the topic of how widely SE is held among philosophers of science and scientists.
} 
obviously stand in need of argument in order to produce a convincing Master Argument. Notice that Maxwell's Thesis (premise P1) seems to say nothing less than that almost every scientists is a metaphysical realist of sorts!

\subsection{Preview}

In Sect. 2, we analyse Maxwell's reasoning in favour of Maxwell's Thesis, which is the first premise (P1) of the Master Argument, and judge it unconvincing. We claim that in Maxwell's writings two distinct 'aberrance-arguments' in favour of premise P1 can be discerned; the first is an abductive argument, the second a deductive argument. In Sect. 3, we argue that Constructive empiricism (CE) is, properly conceived, not a version of SE, which means we must reject premise P2. Thus our conclusion will be that Maxwell's attack against CE fails. Briefly, Sect. 2 is devoted to premise P1 and Sect. 3 to premise P2 of the Master Argument. In Sect. 4, we present the results of our analyses and the lessons we have learned along the way. These lessons show that Maxwell's attack has not been in vain but teaches us some valuable lessons about both science and CE.

\section{Does Science Implicitly Accept Metaphysics?}

In this section, we analyse the two aberrance-arguments in favour of Maxwell's Thesis (P1). Below we shall proceed by collecting step-wise the premises of the two aberrancearguments we have discerned so as to reach a position where we can assess them.

\subsection{Aberrant Theories}

Although the aberrance-argument is supposed to apply to science generally, we restrict ourselves to physics, as Maxwell does. We first explain the concept of an 'aberrant version' of a scientific theory. ${ }^{8}$

Consider Newton's theory of universal Gravitation (NG). Consider a so-called aberrant version of it which says exactly the same as NG save for golden balls having a radius of exactly $13 \mathrm{~km}$, for which a different law of gravitation is postulated, saying that the gravitational force is repulsive (NG1), or varies with the inverse-cube of the distance between the balls (NG2). Consider a version of NG which is different from NG only in that $r^{-2}$ in Newton's law of gravitation is replaced with $r^{-(2+\varepsilon)}$, where $\varepsilon$ is an extremely small positive number, say a power of 10 such that $\log \varepsilon=-10^{100}$ (NG3). A Humean nightmare version of NG is NG but in the year 3,000 A.D. the gravitational force will disappear completely in the entire universe (NG4); then some day in that year the sun will not rise tomorrow. Next we have a theory that postulates $t w o$ universal forces between every two bodies, an attractive 'gavitational force', which is twice as strong as the gravitational force of NG, and a repulsive 'ravitational force', which has the same strength as the gravitational force (NG5); so whenever we consider two bodies in accordance to NG5, we always have the sum of the gavitational and the gravitational force (for convenience contracted to 'gravitational force'). We also have a version of NG that says the same as NG but for a

\footnotetext{
${ }^{8}$ All accepted scientific theories are not aberrant. Although Maxwell makes an exception for quantum mechanics (1998, pp. 228-229), we joint him in ignoring this when considering the aberrance-argument.
} 
spatio-temporal region whose spatial part has the size of a marble and whose temporal part is about 1 nanosecond; in this region, located in the Andromeda Nebula during Easter 37 A.D., there is no gravity (NG6). Finally we have a theory like NG but for a two-body system like the Sun and Mercury it postulates a precession of its perihelia which is in exact agreement with observations (NG7). ${ }^{9}$ Notice that NG1-NG4 almost certainly are empirically false (they do not save all the relevant phenomena), although we shall never be absolutely certain about it; NG5 is empirically equivalent to (but ontologically distinct from) NG; NG6 is almost empirically equivalent to NG; and NG7 is empirically more successful than NG because NG7 saves at least one more phenomenon than NG does.

We can go on like this endlessly. We can play this aberrance game with every single accepted physical theory. David Hume can be seen as the first player; Nelson Goodman, with his grue-bleen moves, is another famous player; Maxwell boasts of being a contemporary player, playing the game at its utmost general level. ${ }^{10}$ The imagination is the limit and that is no limit at all. For want of a name, we call regular all non-aberrant theories, such as NG, classical mechanics, classical electrodynamics, the special and the general theory of relativity, thermodynamics, etc.; in fact, all actually accepted theories. ${ }^{11}$ For those who worry about theories of which it is not easy to say whether they are aberrant or regular: do not worry, everything asserted in this paper goes through if you take for 'aberrant' theories only the utterly bizarre ones (there is an infinitude of them too and this is sufficient to get the aberrance-argument going).

Maxwell's aberrance-arguments in favour of premise P1, Maxwell's Thesis, can be found in various places. ${ }^{12}$ Indulge us one quotation in full from the present journal:

But now comes the decisive point. In persistently rejecting infinitely many such empirically successful but grotesquely ad hoc [=aberrant, FAM] theories, science in effect makes a big permanent assumption about the nature of the universe, to the effect that it is such that no grotesquely ad hoc theory is true, however empirically successful it may appear to be for a time. Without such a big assumption as this, the empirical method of science collapses. Science is drowned in an infinite ocean of empirically successful ad hoc theories. ${ }^{13}$

We begin our analysis of the first aberrance-argument by reporting the undeniable social fact that science only accepts regular theories and dismisses aberrant (utterly bizarre) theories without a moment's thought; aberrant theories rarely if ever enter the scientific competition of acceptance and rejection; they seem a typical product of the philosophical

\footnotetext{
9 Cf. Maxwell (1993, pp. 68-70), Maxwell (1998, pp. 51-55).

${ }^{10}$ Maxwell (1974, pp. 128-131), Maxwell (1993, pp. 67-69, 89), Maxwell (1998, pp. 47-54), Maxwell (2002a, pp. 3-5).

11 For further discussion of the distinction regular/aberrant, including a more-or-less precise definition, and of why aberrant theories have to be taken seriously (Hume, Goodman and their commentators did), we refer to Maxwell (1998, pp. 47-56) and Kukla (2001). Since Maxwell's definition is rather elaborate, and since our elucidation of the concept of abberancy by means of several examples (NG1-NG7) ought to be enough to understand this paper, we gloss over it. The very fact that a more-or-less precise definition of abberancy can be given removes a worry that may have arisen, namely that if the explanation of 'an aberrant version of' were to rely on a regular theory being given first, the explanation would have been circular because 'regular' is supposed to mean 'not aberrant'.

12 Maxwell (1974, pp. 128-131), Maxwell (1993, pp. 67-78), Maxwell (1998, pp. 47-64).

13 Maxwell (2002a, pp. 4-5).
} 
imagination run wild. Therefore the first premise of the aberrance-argument is an undeniable truth:

(Ab) Science rejects all aberrant theories and accepts only regular theories

For the sake of future reference, we also formulate the following three theses.

(U) The universe is comprehensible, which by definition means that it is such that it makes all aberrant theories false. ${ }^{14}$

(EmpU) The universe is empirically comprehensible, which by definition means that it $i s$ such that it makes all aberrant theories empirically inadequate; a theory $T$ is by definition empirically adequate iff $T$ saves all the phenomena in the universe it is supposed to save, iff the observable universe is exactly like $T$ says it is.

(Truth) Theory $T$ is true iff $T$ is ontologically adequate, which is to say that $T$ saves all the noumena it is supposed to save, that the universe is exactly like $T$ says it is.

Obviously $\mathbf{U}$ implies EmpU but not conversely. These theses presuppose it makes sense to utter expressions like 'the universe is exactly like', 'the universe is constituted in a certain way', 'the noumena of the universe', and sibling expressions; we emphasise that taking such expressions to be meaningful does not entail any commitments about their truth. Those who hold that only a theory plus an ontology, or plus an 'interpretation', can tell us what the universe is like, rather than a 'bare theory', can take ' $T$ ' to stand for ' $T$ dressed with some ontology (or some interpretation)'. Such a change will not affect the arguments in this paper in any significant sense.

\subsection{Only Methodological Assumptions?}

To find out whether science (implicitly) accepts some thesis, one could, it seems, simply ask a representative sample of scientists whether they accept the thesis or not. But when it is some metaphysical thesis, a poll will not work, Maxwell submits, because scientists are brain-washed with SE (1), the 'official ideology of science'; they will deny they accept any metaphysical thesis about the universe (SE1). ${ }^{15}$ Scientists believe-falsely according to Maxwell (1974, p. 126) - that criticising SE is an act of scientific betrayal. Until further notice we shall not challenge Maxwell's problematic charge of all scientists suffering from a 'false consciousness' (perhaps Oprah Winfrey should have a long talk with our scientists, pronouncing her immortal words: 'Denial is not a river in Egypt.'). We propose to get around the problem in the only way conceivable: by explicitly postulating a certain connexion between the observable behaviour of scientists, as we have reported in $\mathrm{Ab}(2)$, and unobservable assumption-making of scientists, because this is what Maxwell is surreptitiously doing.

\footnotetext{
${ }^{14}$ No claim is being made that the definition of "comprehensible" is in full agreement with everyday use; we need a name for the predicate described in $\mathbf{U}$ and we have chosen "comprehensible" because Maxwell has chosen it. Notice that $\mathbf{U}$ is what Maxwell asserts in the displayed quotation above: "no grotesquely ad hoc theory is true".

${ }^{15}$ Maxwell (1974, p. 126), Maxwell (1998, pp. 41-43), Maxwell (2002a, p. 24). Whether all scientists actually subscribe to SE (1) is for us an open question. Not an open question for us is whether there is a living philosopher of science who defends SE2 (1) - there isn't any.
} 
First we write down this assumption; then we explain it.

(Acc) If someone follows method $\mathcal{M}$ to reach aim $A$, and expects that following $\mathcal{M}$ will help him considerably in reaching $\operatorname{aim} A$, then he accepts the concomitant methodological assumption $\mathbf{U}[\mathcal{M}, A]$, according to which the universe is such that following method $\mathcal{M}$ is of considerable help in reaching $A$.

Surely it is not straightforward to read off which assumptions Albert, say, is making from the methods he follows, because distinct assumptions may lead to exactly the same behaviour. In the light of rampant Duhem-Quine underdeterminacy, one could even turn the tables and defend the opposite: the observable behaviour of a subject does not determine her mental state. Nonetheless there are cases and circumstances where this can be done beyond reasonable doubt, such as in the case of pain-behaviour. But let us consider a more relevant example.

Consider Albert throwing water in the waste-paper basket besides his desk that has caught fire because in a moment of absent-mindedness he threw what was left of a tasty Cuban cigar in it. Can we infer from his behaviour that Albert accepts the Assumption that the universe is such that water extinguishes fire? Presumably we can. But now suppose there happened to be standing an oil-can next to a bucket filled with water. Suppose further that Albert (whose ignorance about mundane matters is legendary) later declares he did not have clue whether oil or water extinguishes fire and that it was sheer luck that he chose to empty the bucket of water on the burning paper in the basket. In this case the ascription of the Assumption to Albert would be wrong. But if Albert tells us he expected to be successful with water and he adds, with raised eyebrows, that of course he would have made the situation worse if he had thrown oil on the flames instead, then the inference to Albert making the Assumption is wholly correct.

So it seems that, to generalise cautiously, if someone applies method $\mathcal{M}$ to achieve aim $A$, and expects that applying method $\mathcal{M}$ will be of considerably help to achieve aim $A$ (if not guarantee success), then he accepts what we shall call the methodological assumption $\mathbf{U}[\mathcal{M}, A]$ of method $\mathcal{M}$ given aim $A$ : the universe is such that applying method $\mathcal{M}$ helps to achieve aim $A$; the height of someone's expectations is a measure of how confident he is in accepting $\mathbf{U}[\mathcal{M}, A] .{ }^{16}$ Well, this is precisely assumption Acc (6) above.

Our next problem is: how do we know what someone expects? We can observe whether someone applies a method, or goes against it, but we cannot observe what his expectations are. They are in his mind. Duhem-Quine underdeterminacy strikes again. Someone may apply a method without cherishing any expectations about its outcome whatsoever (as we have seen in the example with Albert); in that case no assumptions about the universe are made. Clearly what we need is some connexion between observable behaviour and unobservable expectations.

Consider the following example of a methodological rule (Maxwell's example):

$\mathcal{R}$. If theory $T$ does not explicitly assume that all matter consists of atoms

(in the etymological sense) and $T$ does not describe how matter

interacts by means of contact forces alone, then $\operatorname{reject} T$.

\footnotetext{
${ }^{16}$ Cf. Maxwell (1998, p. 10). Notice that any assumption, metaphysical or not, that can be the basis of a rule of how to achieve a particular aim is a methodological assumption. Therefore to say that methodological assumptions are not or cannot be metaphysical is to utter a falsehood.
} 
The concomitant methodological assumption is as follows:

$\mathbf{U}[\mathcal{R}, A]$. Matter is not infinitely divisible, but consists of smallest building blocks that cannot be divided further (the atoms), and pieces of matter, atoms included influence other pieces of matter only by means of contactforces, i.e. they influence each other only when they touch each other.

Here aim $A$ is the epistemic aim of science and it matters little what one takes this aim to be: ontological adequacy (truth), empirical adequacy (empirical truth), explanatory adequacy, and what have you. Now suppose that all physicists apply rule $\mathcal{R}$ (7) scrupulously, time and again, without exception, so that theories assuming the infinite divisibility of matter, theories that operate with action-at-a-distance or with fields, and what theories have you, are all rejected flat out of hand by the scientific community, and that only atomisticmechanistic theories are taken seriously. In this supposed situation we need not inquire whether physicists have higher expectations to be successful when applying rule $\mathcal{R}$ (7) than when they break it (no matter how one construes the aim of physics); it is evident that they do. Actions speak louder than words. Methodological assumption $\mathbf{U}[\mathcal{R}, A](8)$ then surely is accepted. This is no different than when we infer from the observable behaviour of firefighters when there is a fire that they accept the assumption that the universe is such that throwing water on the flames extinguishes the fire. So let us lay down the following general premise:

(Exp) If someone always follows method $\mathcal{M}$, and never goes against $\mathcal{M}$ although nothing prevents him from doing so, then he has higher expectations to be successful when following $\mathcal{M}$ than when going against $\mathcal{M}$.

Assumption Exp (9) postulates a plausible connexion between recurring observable behaviour and unobservable expectations. Exp applied to the supposed behaviour of the imaginary scientific community sketched above leads to the conclusion that the imaginary community accepts an atomistic-mechanistic ontology $\mathbf{U}[\mathcal{R}, A] .{ }^{17}$

By way of an interjection we mention that the Wittgenstein-Ryle insight that the ascription of mental states to subjects happens largely on the grounds of observable behaviour; particular patterns of behaviour are constitutive for the meaning of particular mental state. Assumption Exp (9) can be seen as a particular application of this generally accepted insight: to accept $\mathbf{U}[\mathcal{M}, A]$ in part means to be disposed to display the behaviour of following method $\mathcal{M}$ in order to reach aim $A$.

When we now combine Acc (6) and Exp (9) and apply it to science, we obtain:

(AccExp) If science always follows method $\mathcal{M}$ (for reaching some aim, $A$ say), and never goes against it although nothing prevents science from doing so, then science accepts the concomitant methodological assumption $\mathbf{U}[\mathcal{M}, A]$, which asserts that the universe is such that following method $\mathcal{M}$ is of considerable help (for reaching $A$ ).

The three premises we have gathered so far, Ab (2), Acc (6) and Exp (9), immediately throw a conclusion into our lap via consequence AccExp (10): thesis $\mathbf{U}$ (3) is the

17 Imaginary although strikingly similar to the scientific community of the sixteenth-century... 
methodological assumption of a method that science always follows and never breaks according to $\mathrm{Ab}(2)$ :

Lemma I. Science permanently accepts thesis $\mathbf{U}(3)$

To arrive at premise P1 of the Master Argument from Lemma I, we must argue that thesis $\mathbf{U}$ (3) is both substantial and metaphysical. We take these two attributes in turn.

\subsection{What is a Substantial Thesis?}

When we agree to call a thesis 'substantial' in a particular context iff accepting or rejecting it has consequences that are generally recognised as important in that context, then thesis $\mathbf{U}$ (3) is substantial whenever Maxwell is right that $\mathbf{U}$ is a necessary condition for the possibility of science. No thesis $\mathbf{U}$, no science. Science being possible or impossible is the biggest difference one can imagine in the philosophy of science: no science, no philosophy of science! So let us focus on this particular 'important consequence' so as to make a thesis substantial:

If accepting a thesis is a necessary condition for the possibility of science, then it is a substantial thesis.

Maxwell essentially has erected a 'transcendental deduction'. If science were not to reject all aberrant theories in a single sweep but were to take them seriously, then scientific research and a fortiori scientific progress would come to an end, because scientists would drown in an ocean of aberrant theories of which each theory would have to be tested before it could be rejected, as SE commands. ${ }^{18}$ This testing, however, only works for aberrant theories that are empirically distinct from their regular sibling; science could not get rid of aberrant theories this way that are empirically equivalent to the regular theory or empirically indistinguishable from the regular theory by current experimental means. But this only makes Maxwell's case stronger, because aberrant theories with only aberrancies in the realm of the unobservable cannot be rejected on the basis of experimental tests; the only way to get rid of these abberant theories is to accept thesis $\mathbf{U}$ (3) and act in accordance to it.

This transcendental argument is, however, not correct. Let us hold on to Acc (6) and Exp (9). Then not accepting thesis $\mathbf{U}$ (3) implies via Lemma I (11) that not-Ab (2): science does not reject some aberrant theories but accepts them. Does science, now, come to an end? Let us see.

Suppose all physicists were to agree to accept aberrant gravitation-theory NG1 rather than Newton's regular theory NG (see Sect. 2.1), in agreement with not-Ab (2). Then science would accept, and hence would not reject some aberrant theory. But science would definitely not come an end, let alone become impossible. In general, if scientists were to accept collectively a single aberrant version of every accepted regular theory, then science would not come to end. The only difference with science as we know it would be a few introductory lines in every science book, asserting that a particular aberrancy will be set aside whence-forth. Scientific progress would remain very possible whilst only aberrant theories were accepted, in blatant contradiction to $\mathbf{U}$ (3) - and to Emp $\mathbf{U}$ (4).

${ }^{18}$ Cf. Maxwell (1974, p. 129), Maxwell (1998, pp. 192-193). Witness also the gist of this transcendental deduction in the displayed quotation in the fifth paragraph of Sect. 2.1. 
So it seems we must conclude that Maxwell's transcendental argument is no good: wholly rejecting $\mathbf{U}(3)$ is fully compatible with the possibility and growth of science. But let us be charitable and walk a bit further along this line of reasoning.

Suppose now that every time a new theory (model, hypothesis) is proposed, scientists must convene to decide which aberrant version they choose. That would quickly become quite a drag. Since there are many scientists, a lot of time and effort would be wasted by travelling. Science would not come to an end all right, but it would progress more slowly. But wait a minute, setting up some website where every scientist can make his choice known would be enough. Still a drag when everyday someone else comes up with an aberrant theory. The need would arise for some general guideline to choose between aberrant theories, so that everyone chooses instantly the very same theory (model, hypothesis) and can continue with their research. The simplest guideline we can think of is this one: choose the regular version, or in other words, adopt thesis $\mathbf{U}$ (3) as a methodological assumption about the universe and act in accordance to it.

But now suppose that no one ever proposes an aberrant theory. Then there is no need to adopt thesis $\mathbf{U}$ (3)? Here we go off track, because the very social fact that science hardly ever proposes an aberrant theory is Maxwell's explanandum Ab (2) and the first aberranceargument, which we are currently analysing, is supposed to lead us to the best explanation of this social fact.

Anyhow, Maxwell could argue that adopting $\mathbf{U}$ is, although admittedly not necessary for the possibility of science, it certainly is conducive for the growth of scientific knowledge, and he could submit that this is sufficient to call $\mathbf{U}$ substantial. Let us go along and accept the following sufficient condition for being 'substantial':

(SignSubst) If accepting or rejecting a thesis makes a significant difference in how fast science progresses, then the thesis is substantial.

We have judged Maxwell's transcendental argument for thesis U (3) being necessary for the possibility of science to be unconvincing, but we have also judged it convincing for a weaker thesis, namely the following one:

(SignU) Accepting or rejecting thesis $\mathbf{U}(3)$ makes a significant difference in how fast science progresses.

From SignSubst (13) and Sign U (14) we then have:

(SubstU) Thesis $\mathbf{U}(3)$ is a substantial thesis.

Lemma I (11) and Subst $\mathbf{U}$ (15) together trivially imply

Lemma II. Science permanently accepts a substantial thesis about the universe, namely thesis $\mathbf{U}(3)$.

The last thing we have to establish is whether thesis $\mathbf{U}$ (3) is metaphysical.

\subsection{What is a Metaphysical Thesis?}

Like Popper, Maxwell considers 'scientific' and 'metaphysical' to be predicates of single statements (e.g. hypotheses) and classes of them (e.g. theories). But, unlike Popper, who famously took refutability (if needed given a certain amount of background knowledge) as the criterion for being scientific, Maxwell rejects this criterion to demarcate science from non-science. Considering what is at stake, namely whether science presupposes 
metaphysical theses, one would have expected an elaborate discussion of the subject of demarcation somewhere in Maxwell's opera. Disappointingly no more than a single footnote in his magnum opus is devoted to the subject, from which we shall quote the core passage in full:

A 'metaphysical' thesis, as understood here, is a general, factual thesis about the world which lacks the precision of a physical law or theory, and thus fails to make the precise empirical predictions of a law or theory. ${ }^{19}$

Let us immediately formulate what criterion Maxwell apparently uses and then explain it with the further sparse material on the subject-matter provided by Maxwell.

(Meta) A proposition is metaphysical iff it is a general proposition about the universe which is imprecise and hardly refutable (whenever needed given a certain amount of background knowledge).

The notions of imprecision and being hardly refutable are vague, but that is precisely how Maxwell wants his conception of metaphysics to be: a proposition about the universe is more scientific, and consequently less metaphysical, if it becomes more precise or better refutable (ibid.). Maxwell does not provide a general explication of the notion of precision, but provides two illustrations: (a) All matter is constituted of atoms; and (b) Newton's law of universal gravitation with a completely unspecified constant of gravity. These are general imprecise propositions about the universe (ibid.); by themselves, they make no precise testable predictions and are therefore hardly refutable.

Maxwell's idea seems to be that the less precise a general proposition about the universe is, the less capable it is to contradict particular states of affairs, with irrefutability presumably as the limit of being incapable to contradict any state of affairs whatsoever. We have however put both hardly refutable and imprecision in Meta (17). We shall not further discuss Meta. Instead we focus on the question which is relevant for assessing the Master Argument, namely whether the particular thesis $\mathbf{U}$ (3) counts as metaphysical by Meta (17).

Certainly $\mathbf{U}$ is a general proposition about the universe. So in order to pronounce $\mathbf{U}$ metaphysical, $\mathbf{U}$ must be imprecise or hardly refutable. If, on the contrary, $\mathbf{U}$ turns out to be easy to refute and quite precise, Meta (17) permits us to conclude that $\mathbf{U}$ is not metaphysical.

One problem with arguing for the irrefutability of some statement (or class of statements) is familiar from discussions about Popper's demarcation-criterion. A statement $S$ (or class ...) is irrefutable iff all implications of $S$ are irrefutable, because as soon as a single refutable implication of $S$ is found, this is sufficient (and necessary) to call $S$ refutable. We can never reach the conclusion that $S$ is irrefutable because $S$ has infinitely many implications. So if Maxwell wants to establish the metaphysical character of thesis $\mathbf{U}$ (3), he needs to establish a conclusion that on the basis of Meta (17) is for Earth-dwellers impossible to establish. Therefore any claim of having established that thesis $\mathbf{U}$ is metaphysical will be a non sequitur.

But perhaps this is too quick. Perhaps one should not invoke what is (not) 'impossible for humans' in a philosophical argument. There are, in fact, cases where we can reach the verdict of irrefutability. Suppose we have verified that four statements by themselves are irrefutable, say the Russell-Whitehead axioms of classical propositional logic; then arguably their deductive closure also is irrefutable. Hence it is humanly possible to reach

19 Maxwell (1998, p. 271). 
the conclusion that an infinite class of statements is irrefutable. Is this also the case in $\mathbf{U}$ (3)?

Let us consider again a situation we considered in Sect. 2, where we have Newton's theory of universal Gravitation (NG) and the aberrant version with the golden balls (NG1). When presented with both NG and NG1, thesis $\mathbf{U}$ (3) advices us to prefer NG. But NG1 is just as refutable as NG is, given a certain amount of background knowledge. Two golden balls of $13 \mathrm{~km}$ radius which attract each other at some distance in accordance with Newton's inverse-square law forms a logically possible state of affairs with observable consequences that conflict with NG1. Hence NG1 is refutable. Suppose, for the sake of argument, that we were to find such a state of affairs repeatedly. Then NG1 would stand refuted. If we were to find that the golden balls, in fact, repulse each other, then NG would stand refuted. This much is indisputable.

Now what would be the bearing on $\mathbf{U}$ (3)? If one wants to hold the permanent (implicit) acceptance of thesis $\mathbf{U}$ by science responsible for preferring regular theories over all aberrant versions - as the reasoning in favour of premises Acc (6) and Exp (9) goes (see Sect. 2.2) - , and one praises $\mathbf{U}$ (3) for this excellent methodological advice each time a regular theory is confirmed and a number of its aberrant versions is ipso facto refuted, then consistency in our behaviour of appraisal requires that one must also hold thesis $\mathbf{U}$ responsible when it persistently gives the wrong advice, as in the imagined example above with the repulsive golden balls, and then one should blame $\mathbf{U}$ (3) for that. Contrapositively, if $\mathbf{U}$ (3) were never to carry any blame for giving the wrong advice so as to be immune for refutation, then it could also play no rôle in understanding the practice of science. If we were to live in a universe where frequently aberrant theories turn out to save the phenomena and normal ones do not, then not a single soul would accept thesis $\mathbf{U}$ (3). The conclusion is that thesis $\mathbf{U}$ (3) is vulnerable for experimental findings, if only via the theories that $\mathbf{U}$ selects. The occurrence of any of an infinitude of aberrant phenomena, like the one of the repulsive golden balls, is sufficient to make trouble for $\mathbf{U}$. But this is just to say that thesis $\mathbf{U}$ is very refutable and then, by virtue of criterion Meta (17), $\mathbf{U}$ is not metaphysical.

How about the (lack of) precision of thesis $\mathbf{U}$ (3)? Thesis $\mathbf{U}$ gives unambiguous advice to choose between two very precise theories, such as NG and NG1. An infinitude of such pairs can be proved ad libitum. Then it seems odd to call $\mathbf{U}$ imprecise. Thesis $\mathbf{U}$ (3) will have both refutable and irrefutable consequences, and both precise and imprecise consequences. Should that render $\mathbf{U}$ metaphysical after all? Surely not. All accepted regular scientific theories also have irrefutable consequences, e.g. tautologies, and imprecise ones, e.g. NG entails that planets attract each other inversely proportional to $r^{n}$, where $0<n<10^{10}$. Should we, then, go on and render also all accepted scientific theories metaphysical?

To summarise, thesis $\mathbf{U}$ (3) has an infinitude of precise and refutable implications; it has ton-loads of precise empirical content. Intuitively such a thesis can hardly be called metaphysical. Maxwell's criterion Meta (17) vindicates this intuitive judgment: according to it, $\mathbf{U}$ is definitely not a metaphysical thesis. So the final step, from Lemma II (16) to Maxwell's Thesis, which is premise P1 of the Master Argument, is a non sequitur. Furthermore, it is difficult to see how $\mathbf{U}$ (3) could be called 'metaphysical' by weakening criterion Meta (17) and still having a non-trivial criterion left that would render thesis $\mathbf{U}$ metaphysical and scientific theories not. ${ }^{20}$

\footnotetext{
${ }^{20}$ Logically weakening Meta by replacing 'iff' in (17) with 'if' or 'only if' will not do: if (17) is only a sufficient condition, we have no ground to call thesis $\mathbf{U}$ metaphysical and the non sequitur remains; if (17) is only a necessary condition, then we have no grounds to call $\mathbf{U}$ (3) not metaphysical by virtue of it.
} 


\subsection{Assessment of the First Aberrance-Argument}

We summarise our assessment of the first aberrance-argument. Here is its logical structure:

$$
\begin{array}{clc}
\operatorname{Acc}(6) \wedge \operatorname{Exp}(9) & \longrightarrow & \operatorname{AccExp}(10), \\
\operatorname{AccExp}(10) \wedge \operatorname{Ab}(2) & \longrightarrow & \operatorname{Lemma} I(11), \\
\text { SignSubst }(13) \wedge \operatorname{SignU}(14) & \longrightarrow & \operatorname{SubstU}(15), \\
\text { SubstU }(15) \wedge \operatorname{Lemma~I}(11) & \longrightarrow & \operatorname{Lemma~II}(16)
\end{array}
$$

These four material conditions lead to the following conclusion:

$$
\begin{aligned}
(\operatorname{Acc}(6) \wedge \operatorname{Exp}(9) & \wedge \operatorname{Ab}(2) \wedge \operatorname{SignSubst}(13) \wedge \operatorname{SignU}(14)) \\
& \longrightarrow \operatorname{Lemma} \mathrm{II}(16) .
\end{aligned}
$$

The final step from Lemma II toward Maxwell's Thesis (P1) fails:

$$
(\operatorname{Meta}(17) \wedge \text { Lemma II }(16)) \nrightarrow(\mathrm{P} 1) \text { Maxwell's Thesis. }
$$

Hence the entire first aberrance-argument for P1 fails:

$$
\begin{gathered}
(\operatorname{Acc}(6) \wedge \operatorname{Exp}(9) \wedge \operatorname{Ab}(2) \wedge \operatorname{SignSubst}(13) \wedge \operatorname{SignU}(14)) \\
\not(P 1) \text { Maxwell's Thesis. }
\end{gathered}
$$

The acknowledgment that step (20) of the first aberrance-argument makes it a non sequitur is independent of whatever view one has on science. The same holds for the acceptance of the premises Ab (2), SignSubst (13) and Sign U (14), or so we submit. But it does not hold for the premises Acc (6) and Exp (9), as we shall see presently. In the context of assessing the Master Argument as directed against CE, the relevant question to ask here is whether Acc (6) is objectionable in the eyes of CE. In these eyes, Acc (6) does not seem plausible, because Acc, going from observable behaviour to unobservable mental states, smacks too much of an Inference-to-the-Best-Explanation (IBE), which is a mode of inference that Van Fraassen is very critical about, in particular when it concerns an explanandum about observables only and an explanans which is also about unobservables. ${ }^{21}$ A proponent of IBE would submit that if someone accepts methodological assumption $\mathbf{U}$ (3), then this 'explains' why he expects to be successful when following the associated methodological rule 'reject aberrant theories' (2), and this, in turn, 'explains' why he actually always follows this rule. This is essentially the kind of explanation we provide when we say that Nick is eating (observable behaviour) because he is hungry (his mental state). When we infer from an eating Nick that he is hungry, we make an IBE. Apart from the question whether this really explains anything (this stuff makes people sleepy because it has property $X$ and $X$ has a tendency to make people sleepy), anyone who is critical of IBE in general can now start digging his heels in to resist premise Acc (6).

To show that premise Acc (6) definitely is an IBE in disguise, it is sufficient to provide at least one other explanation; then one can go on to ask why accepting thesis $\mathbf{U}$ is the best explanation, and to ask how Maxwell knows there are not more explanations, and to ask how we know the best one is among the ones we happen to have formulated (it may be 'a bad lot'), etc.

To begin with: what other explanation is there for $\mathrm{Ab}$ (2) but the acceptance of $\mathbf{U}$ (3)? Well, just as there can be other explanations of why Nick is eating besides him being hungry (such as: doctor's orders; it is part of a bet; he is only tasting the food but is not hungry at all; he is acting; he proves to his wife that the food is not tainted; he is being

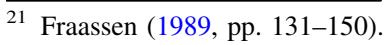


polite to his host who offers food; etc.), there is an alternative explanation for following $\mathrm{Ab}$ (2). This explanation is thoroughly aesthetical in nature: science rejects aberrant theories (Ab) because they are ugly; science operates by means of the following selection-criterion:

Estheticism. A theory $T$ accepted iff so far $T$ has saved all the established phenomena which it is supposed to save and $T$ is beautiful

Criterion Estheticism (22) does not overtly involve metaphysics. A propounder of Estheticism (22) may look upon fact $\mathrm{Ab}$ (2) as a celebration of a remarkable agreement in 'subjective taste', slight individual differences notwithstanding - a 'scientific taste' that is constitutive for the culture of scientific.

We can think of even a third explanation for following $\mathrm{Ab}$ (2), which is thoroughly instrumentalist in nature: science rejects aberrant theories $(\mathrm{Ab})$ because they are unnecessarily complicated to apply, they have redundant epicycles. Science operates by means of the following selection-criterion:

Instrumentalism. A theory $T$ is accepted iff so far $T$ has saved all the established phenomena which it is supposed to save and $T$ is the most easy of all available theories to apply.

Just like criterion Estheticism (22), Instrumentalism (23) does not overtly involve metaphysics. Unlike a propounder of Estheticism, who speaks about aesthetics and the necessity of beauty to make our grey and routine-ridden lives a sense of profundity, a propounder of Instrument (23) speaks about applications and efficiency, praises engineering and inventing useful and useless gadgets to make our grey and routine-ridden lives joyful.

Criterion Estheticism (22) is not entirely a philosopher's fiction that has nothing do to with science as we know it, because certain brilliant physicists considered beautiful theories to be ends in themselves, such as Dirac, and Weinberg [1992, p. 165]: "And in any case, we would not accept any theory as final unless it were beautiful." Instrumentalism (23) seems a little less likely to be such a fiction. Nonetheless we are prepared to adopt the conjecture that scientists reject aberrant theories not because these theories go against their personal, subjective, contingent taste ('ugly') or are unnecessarily clumsy to be efficiently applied, but because scientists are more likely to accept in their hearts that Mother Nature simply does not work in the way aberrant theories say She works-which is precisely what thesis $\mathbf{U}$ (3) captures. How to justify this conjecture when we cannot ask scientists because they suffer from having a false consciousness called 'Standard Empiricism', as Maxwell would have it? Anyhow, sceptics about IBE such as Van Fraassen now certainly have some ground to stand on. Whether or not criteria Estheticism (22) and Instrumentalism (23) have anything to do with actual science is irrelevant. What is relevant is that there is more than one explanation conceivable and this is enough to demonstrate that Acc (6) is an IBE in disguise.

Perhaps this is the appropriate moment to wave a red flag against Maxwell's psychiatric diagnosis of scientists collectively suffering from a false consciousness or even a neurosis (Sect. 2.2). We believe it is possible to explain to any individual scientist carefully the issues we have been discussing so far, drawing the distinctions we have been drawing and will be drawing (e.g. between acceptance and belief); and then go on to ask her whether she accepts thesis $\mathbf{U}$ (3), or believes $\mathbf{U}$ to be true, or counts $\mathbf{U}$ to our scientific knowledge about the universe, then to repeat the same questions about $\operatorname{EmpU}$ (4), and so to obtain honest and fully conscious answers about the issue at hand. We expect that every scientist will 
declare at least that he accepts thesis $\mathbf{U}$ (3) as a 'working hypothesis' until the facts tell otherwise, because not making it would slow down the growth of scientific knowledge considerably, and because no aberrant fact has been established so far. As we shall see, such acceptance of thesis $\mathbf{U}$, as Lemma I (11) says, and the acknowledgment that $\mathbf{U}$ is substantial, as Lemma II (16) says, do not have the sensational philosophical consequences Maxwell believes they have.

Hence our conclusion about the first aberrance-argument (18) remains that Lemma II (16) is plausible, but the step to Maxwell's Thesis (P1) is a non sequitur because thesis $\mathbf{U}$ (3) is not a metaphysical thesis according to Maxwell's own criterion Meta (17) — or according to any non-trivial weakening of Meta for that matter. Critics of IBE, to repeat, will not even find Lemma II plausible because it relies on the IBE-like premise Acc (6). So it seems that CE is already in the clear.

\subsection{Deductive Logic}

There is a second aberrance-argument present in Maxwell's writings (although it surfaced most explicitly in correspondence) which prima facie circumvents the issue of IBE and purports to be a strictly deductive argument, in particular without having to appeal to premises Acc (6) or Exp (9). This second aberrance-argument has premise Ab (2) in common with the first one. Its second premise is the following eminently reasonable premise:

(Closed) If one accepts a proposition and is aware of the logical fact that this proposition entails another proposition, then one must accept that other proposition too.

Premise Closed is part of accepting deductive logic, which we take to mean (no more than) the following.

(Logic) Deductive logic is accepted: (a) acceptance of all theorems of deductive logic; (b) rejection of all their negations, which are the contradictions; (c) acceptance of a piece of reasoning as valid if in it only deduction-rules from deductive logic are correctly applied; and (d) Closed (24).

For 'deductive logic' various kinds of logic can be substituted; in this paper we substitute elementary classical predicate logic, which includes classical propositional logic.

Let us put to rest one worry that may arise here. The worry is that since physics accepts both Newtonian Gravity (NG) and Einstein's General Theory of Relativity (GTR), physics by implication accepts contradictions because these theories contradict each other, and therefore (!) physics rejects classical deductive logic. Long live paraconsistency? Physics certainly does not accept these two theories unconditionally, but in relation to a class of phenomena, characterised in terms of the scale of certain physical magnitudes. When we deal with gravitation-phenomena on the grand cosmic scale, GTR is accepted, not NG; when we deal with gravitation-phenomena and only want a comparably small number of significant digits in the results of calculations, NG is accepted; and when we deal with gravitation-phenomena 'at the Planck-scale', neither NG nor GTR is accepted. When we talk about the acceptance of the 'ontology' of two conflicting theories, the one (if any) of the empirically best theory will be accepted. In this manner the acceptance of contradictions is avoided. 
We now proceed to the second aberrance-argument.

\subsection{Assessment of the Second Aberrance-Argument}

Suppose physics accepts theory $T$. Then by virtue of $\mathrm{Ab}(2)$, theory $T$ is regular. Let $T^{*}$ be an aberrant version of $T$. Then $T$ and $T^{*}$ contradict each other precisely there where $T^{*}$ differs from $T$; this is logically the same as: if $T$, then not- $T^{*}$. Then physics also accepts not- $T^{*}$, as premise Closed (24) prescribes.

But what is 'not- $T^{*}$ '? Recall that $T^{*}$ is, for Maxwell, an infinite class of statements. The statements which $T^{*}$ has in common with $T$ must not be denied, otherwise physics is accepting contradictions; all the other statements can be denied and these denials belong to 'not- $T^{*}$ ', as long as they are consistent with $T$. The negations of statements of $T^{*}$ that do not belong to the language of $T$, abbreviated by $\mathcal{L}(T)$, can be lumped into 'not- $T^{*}$ ' without any danger of contradictions arising. Let us call the ensuing class of statements the Negation of $T^{*}$ with respect to $T$ (with a capital $N$ ), denoted by

$$
N\left(T^{*}, \mathrm{~T}\right) \equiv\left\{\neg S \in \mathcal{L}\left(T^{*}\right) \mid S \in \mathcal{L}(T) \longrightarrow\left(\operatorname{Con}(T, \neg S) \wedge S \in T^{*}\right)\right\},
$$

where $\operatorname{Con}(T, \neg S)$, denoting the consistency of class $T \cup\{\neg S\}$, is defined as no contradiction being derivable from $T \cup\{\neg S\}$. Since $T^{*}$ is arbitrary, we arrive at the following result:

Lemma III. Science accepts the negation of every aberrant version of an accepted regular theory $T$ in so far as it is compatible with $T$, which is to say that science accepts the Negation $N\left(T^{*}, T\right)$ (26) of every aberrant version $T^{*}$ of $T$.

Lemma III (27) does not say that science accepts thesis U (3), like Lemma I (11) does. Or does it? Let us see. Lemma III asserts that science accepts lots of denials and thus does not accept, and usually rejects, the corresponding affirmations. These denials make assertions about (certain aspects of) the universe. Hence science accepts an infinitude of assertions about the universe, all of the type asserting that the universe is not like such and such (because they are denials). But is accepting all denials of aberrant statements not tantamount to accepting thesis $\mathbf{U}$ that the universe is comprehensible (3)? Clearly, in the light of Lemma III, it is not consistent to accept not-U. That is to say, Lemma III (27) and Logic (25) imply

Lemma IV. Science does not accept that the universe is incomprehensible, that is to say, science does not accept $\neg \mathbf{U}(3)$.

When we adopt the extremely plausible principle that false theories (and known to be so) are rejected, and recall that accepting classical logic (25) includes accepting that a nonfalse statement is true, then we have the following equivalent formulation of Lemma IV:

Lemma IV . Science does not accept that the universe is such that it makes even

a single aberrant theory true.

Lemma IV entails that science does accept thesis $\mathbf{U}$ (3) if, and only if, the following principle is adopted:

(Neg) Not accepting a proposition implies accepting its negation. 
For if science refuses to accept not-U, principle Neg (30) says that science does accept the negation of not-U, which is $\mathbf{U}$ (according to classical logic a double denial implies an affirmation). So Lemma IV (28) and Neg together imply Lemma I (11), but Lemma IV (28) alone does not imply Lemma I.

Here is the logical structure of the second aberrance-argument:

$$
\begin{aligned}
& \text { Logic (25) } \\
& \mathrm{Ab}(2) \wedge \text { Closed (24) } \\
& \text { Lemma III }(27) \wedge \operatorname{Logic}(25) \\
& \operatorname{Lemma} I V(28) \wedge \operatorname{Logic}(25) \wedge \mathrm{Neg}(30) \longrightarrow \operatorname{Lemma} I(11) .
\end{aligned}
$$

This leads to the following valid argument for Lemma I, which to recall states that science permanently accepts thesis $\mathbf{U}(11)$ :

$$
\mathrm{Ab}(2) \wedge \operatorname{Logic}(25) \wedge \operatorname{Neg}(30) \longrightarrow \text { Lemma I (11). }
$$

From here one can proceed as in the last line of the first aberrance-argument (18). Compare (31) to the argument for Lemma I in this first aberrance-argument:

$$
\operatorname{Ab}(2) \wedge \operatorname{Acc}(6) \wedge \operatorname{Exp}(9) \longrightarrow \text { Lemma I (11) }
$$

In contrast to argument (33), which was abductive in nature due to premise Exp (9), we have a valid deductive argument for Lemma I (32) without premises that smack of IBE, i.e. Exp (9)-anathema to CE. But now we have to ask whether principle Neg (30) is a reasonable premise in (32). Before we answer this, we point out that Neg is not included in accepting Logic (25). ${ }^{22}$ To return to our question, it is one thing to say that every proposition is either true or false, and that one either has to accept or not to accept it, but it is quite another thing to say that one either has to accept every proposition or to accept its denial, which is what principle Neg (30) entails. It seems perfectly reasonable not to accept a certain proposition and also not to accept its denial. To put it another way, if principle Neg is reasonable, then doubt or a neutral attitude is not reasonable anymore, because to doubt a proposition, or remaining neutral with regard to it, involves precisely neither accepting nor rejecting it. But surely there are such things as reasonable doubt and remaining neutral!

So it seems that on the basis of Ab (2) and Closed (24), we cannot reach deductively beyond Lemma IV (28), in particular we cannot reach Lemma I (11). Then we cannot reach Maxwell's Thesis (P1) either.

Finally, it serves to mention that it is quite straightforward to arrive at Lemma I (11) from Lemma IV (28) by means of an IBE, where Lemma I, then, is the admittedly trivial explanans and Lemma IV the explanandum: science does not accept that the universe is incomprehensible because science permanently accepts that the universe is comprehensible. If arrived at Lemma I, and then at Lemma II (16) by virtue of conclusion Subst $\mathbf{U}$ (15), the same problem we faced in the case of the first aberrance-argument stares one in the face: $\mathrm{U}$ is not a metaphysical thesis by virtue of Meta (17) because it boasts with precise empirical content.

\footnotetext{
22 Only in the case one has accepted a so-called 'deductively complete theory' (meaning: if statement $S$ is not provable in the theory, then not- $S$ is a theorem), this holds for sentences in the language of that theory. Such cases are extremely rare; most theories, in so far as investigated by formal means, turn out to be deductively incomplete.
} 
We end by drawing attention to the fact that Standard Empiricism (SE) still stands firmly on its feet (and so does CE), because without Maxwell's Thesis (P1), conclusion C1 of the Master Argument is a non sequitur.

\section{Constructive Empiricism Confuted?}

In the previous Section we have concentrated on the arguments Maxwell has propounded in favour of premise P1 of the Master Argument and we found them unconvincing. But the Master Argument also relied on a second contentious premise (P2), asserting that CE is a version of Standard Empiricism (SE). In the present section we focus on premise P2. Our conclusion will be that $\mathrm{P} 2$ is false, but can be made true when SE is substantially revised.

\subsection{Some Principles of Constructive Empiricism}

Van Fraassen's CE is generally held to be the only well-developed non-instrumentalist alternative to the varieties of realism; it proudly stands in the tradition of British Empiricism and the Vienna and Berlin Circles. ${ }^{23} \mathrm{We}$ first rehearse a few tenets of CE which we need for our present purposes; then we judge Maxwell's assertions about CE in the Master Argument, in particular premise P2.

Fundamental for $\mathrm{CE}$ are two distinctions: a distinction between pragmatic acceptance of a proposition or a theory and the epistemic doxastic belief in the proposition, thinking that it is true (two different propositional attitudes, each having different implications); and an admittedly vague and anthropomorphic yet perfectly meaningful distinction between observable and unobservable objects. For Van Fraassen, science is neither a wholly epistemic endeavour (as it was for logical-positivists and it is for most if not all realists) nor a wholly pragmatic endeavour (as it is for instrumentalists), but it is a mixture of both.

Let $T$ be a scientific theory. $T$ is called empirically adequate iff $T$ saves every relevant phenomenon, observed or not, in the past, present and future of our universe; and $T$ is logically adequate iff $T$ does not produce contradictions. Consider the following conditional:

\section{If someone accepts theory $T$, then this involves the doxastic belief that $T$ is both logically and empirically adequate.}

(Since inconsistent theories cannot be empirically adequate, the first necessary condition of acceptance can be deleted.) A constructive empiricist believes no more about an accepted theory than what is mentioned in the necessary condition in (34), and remains neutral with regard to any further additions going beyond the observable, whereas a realist believes more, like that the accepted theory is also ontologically adequate, as in Truth (5), so that it also tells us the truth about what happens in the unobservable part of the world. Then being a constructive empiricist and being a realist are logically incompatible categories; what they share, however, is their obedience of (34). ${ }^{24}$

Van Fraassen gladly permits scientific virtues such as simplicity, explanatory power, unifying capacity, and a fortiori being regular (non-aberrant) to play a rôle in the decision to accept or to reject a scientific theory (as they unquestionably do), but holds that these

\footnotetext{
23 See Fraassen (1980, 1989).

24 Cf. Fraassen (1980, pp. 8, 12, 1989, p. 193).
} 
scientific virtues are not epistemic virtues. For CE, the only epistemic virtues are logical and empirical adequacy. Yet in spite of their being epistemically void, they are scientific virtues nonetheless, because having them is expedient for reaching the aims of science, in particular the epistemic aim of science:

(CEP1) Epistemic Aim of Science. The epistemic aim of science is empirical truth, i.e. the construction of (logically and) empirically adequate theories.

Let it finally be noted that Van Fraassen is a fastidious epistemologist; he rarely speaks of 'knowledge' or 'scientific knowledge'. Nevertheless one can identify in CE at least three genuinely Epistemic Principles; one of which is CEP1 (35), stating what the epistemic aim of science is, the other two being the ones below. This should not come as a surprise, because the core business of the fabric of science is the production of knowledge. Below an accepted scientific proposition is a proposition that is licensed by some accepted scientific theory.

(CEP2) Epistemic Policy. A proposition counts as scientific knowledge, and is believed to be true, iff it is an accepted scientific proposition and is about observables only; if the accepted scientific proposition is also or only about unobservables, it does not belong our scientific knowledge, it is neither believed nor disbelieved (one remains neutral qua belief), but is only accepted.

(CEP3) Scientific Virtues. Logical and empirical adequacy are the only two epistemic virtues; all other virtues are pragmatic; all scientific virtues, epistemic as well as pragmatic ones, are permitted to play a part in the decision to accept or to reject a scientific theory.

\subsection{Constructive Empiricism Contradicts Standard Empiricism}

For CE, not only the evidence decides whether to accept or to reject a theory (37), contrary to part SE2 of Maxwell's characterisation of SE (1) of the Master Argument. So CE contradicts SE2 and therefore is not an instantiation of SE. This makes Premise P2 of the Master Argument false (see Sect. 1).

Furthermore, CE contradicts condition SE1 of SE (1), because according to principles CEP2 (36) and CEP3 (37), CE can accept thesis $\mathbf{U}$ saying that the universe is comprehensible (3). In so far as $\mathbf{U}$ has implications about actual observables, principle CEP2 says one must and therefore surely can believe these implications are true; that is to say, CE commits us to believing in the truth of EmpU (4) as soon as $\mathbf{U}$ is accepted-as Lemma I (11) says that science does. This contradiction between CE and SE1 leads us, again, to conclude that premise P2 of the Master Argument is false.

Surprisingly, we can move beyond mere logical compatibility between accepting thesis U (Lemma I) and CE. Van Fraassen has enriched CE with a 'libertarian' concept of rationality: rationality is 'bridled irrationality'. A person acts irrational iff he sabotages his own aims; and rational iff he doesn't. With regard to belief, we could then say that believing a proposition is rational iff one is not compelled to disbelieve it; hence irrational iff one is compelled to disbelieve it. ${ }^{25}$ One remarkable consequence is that believing in the

$\overline{25}$ Fraassen (1989, pp. 171-172). 
existence of electrons, something which goes against epistemic principle CEP2 (36), is deemed rational, as is disbelieving it and as is remaining neutral about it. From these consequences it should not be concluded that $\mathrm{CE}$ has become inconsistent, but that $\mathrm{CE}$ embraces a 'libertarian' notion of rationality that can make contradicting views of science all rational. We now submit that qua scientists scientists are compelled to act in accordance to methodological assumption $\mathbf{U}$ (3) in order not to slow down needlessly the process of progressing towards the aim of science (35). Then it is irrational for science to reject thesis $\mathbf{U}$ and not follow the associated methodological rule 'reject aberrant theories'. Therefore it certainly is rational to accept $\mathbf{U}$ and act accordingly. With rationality backing us up, we now have moved beyond mere logical compatibility of accepting CE and thesis $\mathbf{U}$ (3), as promised-and this conclusion is even more painfully dissonant to premise P2 of the Master Argument.

\subsection{Two Varieties of Standard Empiricism}

Lately Maxwell (1998, p. 37) has drawn a distinction between two varieties of SE (our emphasis):

We can, in fact, distinguish two versions of SE which differ on just this question of whether empirical considerations ought alone to determine choice of theory in science, or whether simplicity considerations [e.g. whether being regular or aberrantFAM] are important and legitimate in addition to empirical considerations. Let us call the first view bare $\mathrm{SE}[\mathrm{bSE}]$ and the second dressed $\mathrm{SE}[\mathrm{dSE}]$.

So far we have been considering the bare version (bSE); it was twice incompatible with CE and therefore rendered premise P2 twice false (Sect. 3.2). Let us see whether a version of the Master Argument with dressed SE (dSE) can touch CE.

Clearly the weakening of bSE to dSE that Maxwell considers only affects SE2 (Maxwell: "differ on just this question ..."), not SE1 (1). Thus we now have:

\section{Dressed Standard Empiricism (dSE):}

(SE1) Science does not accept any permanent, substantial, metaphysical assumptions about the universe (independent of the evidence and certainly never in violation of the evidence) (1); and (dSE2) the decision to accept or to reject a scientific theory is generally based on empirical grounds (the available evidence) and non-empirical grounds (regularity, simplicity, explanatory force, unifying power and perhaps more).

CE endorses dSE2 (38) wholeheartedly because principle CEP3 (37) of CE entails dSE2. But CE remains incompatible with dSE because, as we demonstrated in the previous Section, it is incompatible with SE1 (1), which is part of dSE (38). Hence we conclude that the move from bare to dressed SE in order to make trouble for CE helps but it does not help enough. CE is a more liberal species of empiricism than both bSE (SE 1) and dSE (38), and therefore immune for the Master Argument. Premise P2 of the Master Argument remains false.

\subsection{A Third Variety of Standard Empiricism}

In contradiction to the conclusion we have just drawn, namely that $\mathrm{CE}$ is neither a variety of bare SE nor of dressed SE, Maxwell claims that CE is a variety of bSE: 
However, Van Fraassen is emphatic that only empirical considerations can legitimately decide what is accepted as scientific knowledge, simplicity having here no role to play whatsoever: it is this that makes him a proponent of bare SE. ${ }^{26}$

When Maxwell claims that in CE "only empirical considerations can legitimately decide what is accepted as scientific knowledge", he misunderstands CE completely, because prior to finding out whether a proposition is about observables only (the stage where "only empirical considerations ..."), it first needs to be ascertained whether this proposition is part of an accepted scientific theory and at that stage non-empirical considerations can legitimately help to reach a decision of acceptance or rejection CEP3 (37); in the entire two-stage process of deciding whether a proposition counts as knowledge not only empirical considerations are legitimate. Maxwell has ignored the first stage.

What Van Fraassen (1980, p. 4) means when he says things like “... pragmatic virtues do not give us any reason over and above the evidence of the empirical data for thinking that a theory is true" is that these virtues play no rôle at the second stage; their rôle is restricted to the first stage. If we have two empirically equivalent theories and one theory evidently has more explanatory power than the other one, then we accept that one because we think this move is conducive for reaching the aim of science (35); but we do not believe that the explanatory theory is closer to the truth, more likely to be true, or whatever genuinely epistemic concept (by the lights of CE) you want to use here. The dunghill of history is filled with false explanatory theories.

The only way to save what Maxwell is trying to say here is to take him as shifting the entire Master Argument from the pragmatic stage of acceptance \& rejection to the epistemic stage of belief \& disbelief, of scientific knowledge. This interpretation is in harmony with Maxwell's more recent formulations of SE, in particular of SE1: ${ }^{27}$

no substantial thesis about the world being permanently upheld as a part of scientific knowledge independently of empirical considerations.

We point out that here the "substantial thesis" is no longer called 'metaphysical', as in his (1974) passim. But since in Maxwell's own conception of science the whole of knowledge is subdivided in ten levels and he calls all levels beyond level 1 (the evidence) and level 2 (theories) "metaphysical, cosmological assumptions concerning the comprehensibility and knowability of the universe" $(1998$, p. 6), we can be certain that the "substantial thesis" in the quotation displayed above still deserves to be called metaphysical. ${ }^{28}$

Let us thus define 'revised dressed Standard Empiricism' as follows:

\section{Revised dressed Standard Empiricism $\left(d S E^{*}\right)$ :}

$\left(\mathrm{SE} 1^{*}\right)$ Science does not take any permanent, substantial, metaphysical assumptions about the universe (independent of the evidence and certainly never in violation of the evidence) as a part of scientific knowledge; and (dSE2) the decision to accept or to reject a scientific theory is generally

based on empirical grounds (the available evidence) and non-empirical grounds (regularity, simplicity, explanatory force, unifying power and perhaps more) (38).

\footnotetext{
26 Maxwell (1998, p. 38).

27 In Maxwell (1998, p. 2); cf. Maxwell (2002a, pp. 1-2).

${ }^{28}$ Cf. Maxwell (1993, pp. 66-69, 2002a), and Section 3.6 for this topic.
} 
In comparison to dressed Standard Empiricism (dSE) (38), this revised version of it (dSE*) has a different, stronger first conjunct: SE1* rather than SE1 (38); in comparison to Standard Empiricism (SE), this revised version of dressed Standard Empiricism (dSE*) has two different conjuncts: the stronger SE1 ${ }^{*}$ rather than SE1 (1) and the weaker dSE2 (38) rather than SE2 (1).

Another way of putting Maxwell's move from dressed SE (dSE (38)) to dSE* (39) is to say that he surreptitiously changes the meaning of 'acceptance': from acceptance in Van Fraassen's sense of pragmatic acceptance simpliciter to acceptance in Van Fraassen's sense of 'epistemic acceptance', as doxastic belief, as being 'part of scientific knowledge'. If we were to put it like this, then another line of attack on CE would ensue, because also in this sense Maxwell would not commit the fallacy of equivocation with respect to 'acceptance', provided we change the meaning of 'acceptance' everywhere in the Master Argument accordingly and take 'scientific knowledge' in Van Fraassen's epistemic sense-otherwise another fallacy of equivocation would be committed. And if SE1 (1) was always intended to be understood as SE1* (39), then what follows next is directed at the Master Argument thus understood.

The global logical structure of the Master Argument (Sect. 1) remains unaffected by these surreptitious changes, but we now have to review our assessment of premises P1 and $\mathrm{P} 2$. Premise P2 now reads that $\mathrm{CE}$ is a version of Revised dressed Standard Empiricism (dSE*) because it meets both of its characterising conjuncts, SE1* (39) and dSE2 (38). We have already seen that CE instantiates dSE2. Does it instantiates SE1* too? When metaphysical theses are such that they do not face the tribunal of sense experience, in agreement with Meta (17), CE will never consider such theses as candidates for entering the body of scientific knowledge, in agreement with requirement SE1* (39). Hence CE is a version of revised dressed Standard Empiricism (dSE*), which makes premise P2 of the revised Master Argument true. So far so good.

But now to make premise P1 true, or at least plausible, it is insufficient for an aberrance-argument to establish that science accepts thesis $\mathbf{U}$ that the universe is comprehensible (3), as Lemma I (11) asserts. One must establish a logically stronger version of Lemma I (11), namely that science accepts $\mathbf{U}$ as part of scientific knowledge in Van Fraassen's sense; from this we then have to go to a stronger, epistemic version of Maxwell's Thesis (P1). Let us consider the two aberrance-arguments in turn, which are supposed to ground premise $\mathrm{P} 1$.

Revised First Aberrance-Argument. This argument clearly needs a stronger version of AccExp (10); namely the following one:

(AccExp*) If science always follows method $\mathcal{M}$ (for reaching some aim, $A$ say), and never goes against it although nothing prevents science from doing so, then the concomitant methodological assumption $\mathbf{U}[\mathcal{M}, A]$ that the universe is such that following method $\mathcal{M}$ is of considerable help (for reaching $A$ ) belongs to the scientific knowledge of the universe.

The ensuing argument arriving at an epistemic version of Lemma I (11) begins to look suspiciously much like a petitio principii: if one is prepared to accept premise AccExp* (40) without further argument, then one might as well accept an epistemic version of Lemma I right away.

But in fact, assumption AccExp* (40) is not plausible for CE. Since for CE what belongs to our scientific knowledge is the object of true belief and can only involve actual 
observables, assumption AccExp* is, then, telling us we can read off (what scientists take to be) scientific knowledge from their observable behaviour. This is generally implausible: one can act against one's own beliefs: out of desperation, or out of habit, to please someone you love, and so forth. We are dealing here, in assumption AccExp* (40), with a fully fledged IBE. This is sufficient to conclude that CE- a sworn enemy of IBE-is certainly not compelled to accept premise AccExp* of the revised first aberrance-argument and by implication not its conclusion either.

Furthermore, we want to point out the following. For CE, the pragmatic acceptance of thesis $\mathbf{U}$ (3) already involves an epistemic commitment according to CEP2 (36) of CE, namely to believe that thesis $\mathbf{U}$ (3) is empirically adequate, i.e. that thesis $\operatorname{Emp} \mathbf{U}$ (4) is true. This is to say that EmpU is part of our scientific knowledge of the universe in Van Fraassen's sense! If Maxwell were to respond that counting EmpU to our scientific knowledge is not enough, and that CE must count the logically stronger thesis $\mathbf{U}$ to our scientific knowledge, then this would be tantamount to demanding CE to betray one of its constitutive epistemic principles (CEP2), namely to withhold belief in anything that goes beyond the actual observable (36). But the debate whether this principle (CEP2) is good or bad is quite another debate; more importantly, Maxwell did neither direct the Master Argument against this principle nor did this principle play a part in the Master Argument. The conclusion is that Lemma I (11) implies, for CE, that EmpU (4) is part of scientific knowledge. Since this is not in conflict with $\mathrm{CE}$, this provides no ground for the rejection of CE.

Revised Second Aberrance-Argument. See above.

Our assessment is that the revised Master Argument, with revised dressed Standard Empiricism (39) replacing Standard Empiricism (1) and concomitantly revised premises, is an improvement on the original Master Argument because it turns the false premise P2 into a true one. But the revised Master Argument is a deterioration when it comes to premise P1; the original aberrance-arguments could plausibly reach Lemma I, stating that science accepts thesis $\mathbf{U}$ (3), but a revised Lemma I (11), stating that science counts $\mathbf{U}$ to our scientific knowledge, can no longer be reached plausibly because the IBE-type premise AccExp* (40) is not quite at home in CE.

\subsection{Varieties of Acceptance}

In the present context, prima facie five notions of 'acceptance' are to be distinguished: ${ }^{29}$

(Acc) Van Fraassen's pragmatic acceptance of a proposition, with or without some particular aim in mind.

(T) Van Fraassen's epistemic acceptance of a proposition, acceptance of it as part of our scientific knowledge (in Van Fraassen's sense of about observables only), of doxastic belief, of thinking that it is true.

(Post) Maxwell's acceptance as 'part of our conjectural a posteriori scientific knowledge'.

(Prior) Maxwell's acceptance as 'part of our permanent a priori scientific knowledge'.

(Sc) Acceptance as understood by science (whatever that is).

A systematic comparison of all five notions is not needed for our present purposes of criticising Maxwell. But to keep seeing the wood between the trees, and, more importantly,

${ }^{29}$ Fraassen (1980, pp. 11-13, 46, 88, 1989, pp. 191-193), Maxwell (1998, p. 20). 
to prevent any worries about our critical analyses from arising in the light of these varieties of acceptance, the following remarks should be enough.

Maxwell intends his (Post) to be the same as (Sc). This collapses one distinction. Next, in order not to let Maxwell commit the fallacy of equivocation with respect to 'acceptance' in his criticism of CE, each of (Acc) and (T) can be chosen in the Master Argument, provided we choose consistently. This is precisely what we have done in the previous Sections: on both accounts the Master Argument against CE failed. So we now only need to consider the two other notions of acceptance which are left: (Prior) and (Post).

If Maxwell were to use 'acceptance' in the Master Argument in any of his two senses of (Prior) or (Post), and not in any of Van Fraassen's two senses of (Acc) or (T), he might still have evaded the charge of committing the fallacy of equivocation, because certain logical relations seem to obtain between his and Van Fraassen's notions of acceptance. Maxwell could, perhaps, erect some version of the Master Argument on the basis of these logical relations. We believe, however, that the prospects for this project are dark, as we shall argue next.

Since (Post) certainly implies (Acc), the premises of a version of the Master Argument using (Post) imply the premises of the Master Argument with (Acc). We therefore can reject the version of the Master Argument with (Post) as soon as we reject the version with (Acc). But this is precisely what we have done already. And mutatis mutandis for (Prior), because (Prior) certainly implies (T).

\subsection{Farewell to Metaphysics?}

In the previous Sections we have seen that Maxwell's Thesis (P1) does not follow from Lemma II (16) by means of Meta (17) and that the prospects of weakening Meta seemed dark because thesis $\mathbf{U}$ (3) boasts with precise empirical content. Now what if Maxwell simply deletes 'metaphysical' altogether everywhere in the Master Argument and is satisfied with concluding that science permanently accepts a substantial thesis about the nature of the universe (Lemma II)? Isn't the discussion whether or not to apply a particular adjective to a thesis really that important?

Well, first of all, when we make this move, we shall have taken a sting out of the Master Argument. The slogan of the Master Argument-Science Presupposes Metaphysics!which attracts the attention of the philosopher of science, then must go. Does there nonetheless remain something philosophically exciting left?

Deleting 'metaphysical' everywhere yields yet another weakened version of SE, a version, to be sure, which is no longer hostile to making metaphysical assumptions. The view which then seems to be under fire of the Master Argument we call 'Heraclitism' (after the pre-Socratic philosopher who said that panta rhei):

Heraclitism. Science does not accept any permanent, substantial assumptions about the universe.

To relate Heraclitism (41) to SE (1): it is a further weakening of its first conjunct (SE1), and it has no second conjunct. Whether Heraclitism still deserves to be called an instantiation of empiricism is difficult to say, in particular in the light of the anti-metaphysical attitude of empiricists generally, as is expressed in SE1 (1) and in SE1* (39). Anyhow, we can hardly call Heraclitism (41) a 'fourth variety of Standard Empiricism'. For reasons that by now need not be rehearsed, a revised premise $\mathrm{P} 2$, stating that ' $\mathrm{CE}$ is an instantiation of Heraclitism', is false, because nothing in CE forbids us to accept permanently some 
substantial thesis like $\mathbf{U}$ (3) when this helps to achieve the aim of science (35). CEs pragmatism makes room for this.

Further, we need to ask whether there is some conception of science explicitly defended by some current philosopher of science that includes Heraclitism. Is there really an 'official ideology' of science that proudly embraces Heraclitism (41)? If there is, then Maxwell has a case against it by means of the first aberrance-argument (18) - charitably glossing over possible qualms about IBE with regard to premise AccExp (10). Before it is established that Heraclitism (41) belongs to the 'official ideology' of science, an attack with the first aberrance-argument will result in a sham fight. This is however not to say that the rejection of Heraclitism (41) by science is not an interesting insight into the nature of science.

\section{Exitum: What to Conclude?}

\subsection{Summary}

Our overall conclusion is that Maxwell has made it plausible that science permanently pragmatically accepts a thesis about the universe (as Lemma I (11) says), namely that the universe is comprehensible, i.e. is such that it makes every aberrant theory false; this thesis U (3) is substantial (Lemma II, (16)) in that it helps science considerably to reach its epistemic aim (15); but thesis $\mathbf{U}$ is not metaphysical (17), because it carries loads of precise empirical content and is very vulnerable to the results of empirical inquiry. Thus Maxwell has failed to make plausible Maxwell's Thesis, which is premise P1 of his Master Argument (Sect. 1), and is the purported consequence of Lemma I (11). Hence Maxwell has also failed to make a case against $\mathrm{CE}$ if $\mathrm{CE}$ had been a version of SE. Both 'aberrancearguments' (18) and (31) we have discerned do not establish Maxwell's Thesis (P1). So as things stand, the step to conclusion $\mathrm{C} 1$ of the Master Argument is a non sequitur. Moreover, premise P2 of the Master Argument, asserting that CE is a version of SE, has turned out to be false.

The revised versions of SE we have considered also fail. The move from 'bare' to 'dressed' SE did not affect our assessment of premise P1 as being groundless-and hence dSE (38) was of no avail-, and both versions of SE did not turn the false premise P2 into a true one. The further move from 'dressed' to 'revised dressed' SE (dSE* (39)), at last, made $\mathrm{CE}$ an instantiation of that $\mathrm{dSE}^{*}$, and this, in turn, made premise $\mathrm{P} 2$ true. But because of the epistemic nature of dSE* (due to the phrase "as a part of scientific knowledge"), the aberrance-arguments performed even worse to establish the then needed, stronger, epistemic version of Maxwell's Thesis (P1), now to be formulated in terms of 'taking a thesis as part of our scientific knowledge'. One reason is that Inferences-to-the-Best-Explanation (IBE) were needed to establish an epistemic version of Lemma I (now asserting that science counts thesis $\mathbf{U}$ to belong to our scientific knowledge of the universe), which is a type of inference that has been severely criticised by Van Fraassen and is definitely not part of $\mathrm{CE}$-ironically, Maxwell rejects IBE too.

Does Maxwell's attack, then, has taught us nothing valuable at all? Not so.

\subsection{Lessons}

We have learned the following four lessons. 
A. Science acts scrupulously in accordance with the methodological rule 'reject aberrant theories and accept only regular ones' (2) and therefore pragmatically accepts a very general methodological assumption about the universe, namely thesis $\mathbf{U}$ : all aberrant theories are false (3).

B. Bare Standard Empiricism (SE) is a false conception of science because of its false conjunct SE2 (1): the decision to accept or reject a scientific theory is never exclusively based on the available evidence, which is in harmony with the acceptance of the UnderDetermination Thesis.

C. Constructive Empiricism can accept thesis $\mathbf{U}$ (3) and can even justify this acceptance, first, by pointing out that following the associated methodological rule (2) helps science significantly to achieve its epistemic aim, which is the construction of empirically adequate theories (35); and, secondly, by arguing on the basis of CE's libertarian view of rationality that it is irrational to reject $\mathbf{U}$ (3) and therefore rational to accept $\mathbf{U}$ and act accordingly. (CE might even claim that $\mathbf{U}$ is a piece of metaphysics neither of the pre-Kantian nor of the inflationary kind, thus making $\mathbf{U}$ an piece of 'empiricist-good' metaphysics for CE.)

D. CE can even believe that thesis $\mathbf{U}$ (3) is empirically adequate and can count thesis EmpU (4) to our scientific knowledge of the universe (in CE's sense of about observables only), because $\mathbf{U}$ boasts with precise empirical content and so far has survived every experimental test.

Acknowledgments Warm thanks to N. Maxwell (London) for exhaustive discussions (electronic and otherwise), to B. C. van Fraassen (Princeton) for his encouragement to publish the current defence of Constructive Empiricism, and to J. N. Butterfield (Cambridge) and D. G. B. J. Dieks (Utrecht) for helpful comments and discussions. Thanks to the Dutch National Science Foundation (NWO) for financial support.

\section{References}

Cohen, L. J. (1992). An essay on belief and acceptance. Oxford: Clarendon Press.

van Fraassen, B. C. (1980). The scientific image. Oxford: Clarendon Press.

van Fraassen, B. C. (1989). Laws and symmetry. Oxford: Clarendon Press.

Kukla, A. (2001). Theoreticity, Underdetermination and the disregard for Bizarre Scientific Hypotheses. Philosophy of Science, 68, 21-35.

Maxwell, N. (1974). The rationality of scientific discovery. Philosophy of Science, 41, 123-153 (Part I), 247-295 (Part II).

Maxwell, N. (1993). Induction and scientific realism: Einstein versus Van Fraassen. British Journal for the Philosophy of Science, 44, 61-79 (Part I), 81-101 (Part II), 275-305 (Part III).

Maxwell, N. (1998). The comprehensibility of the universe. A new conception of science. Oxford: Clarendon Press.

Maxwell, N. (2002a). The need for a revolution in the philosophy of science. Journal for General Philosophy of Science, 33, 1-28.

Maxwell, N. (2002b). Is science neurotic? Metaphilosophy, 33, 259-229.

Maxwell, N. (2005). Popper, Kuhn, Lakatos and Aim-oriented empiricism. Philosophia, 32, 181-239.

Muller, F. A. (2004). Essay review: Maxwell's lonely war. Studies in the History and Philosophy of Modern Physics, 35, 109-119.

Popper, K. R. (1963). Conjectures and refutations. The growth of scientific knowledge. London: Routledge and Kegan Paul.

Rescher, N. (2000). Nature and understanding. The metaphysics and method of science. Oxford: Oxford University Press.

Smart, J. J. C. (2000). Review of Maxwell [1998]. British Journal for the Philosophy of Science, 51, 907911.

Weinberg, S. (1992). Dreams of a final theory. New York: Pantheon Books. 